\title{
Erratum: Step instabilities in Fe/Cu(100) growth [Phys. Rev. Materials 1, 043403 (2017)]
}

Yunsic Shim and Jacques G. Amar

Q (Received 31 January 2018; published 20 February 2018)

DOI: 10.1103/PhysRevMaterials.2.029901

The artificially smoothened configuration shown in Fig. 5(d) of our paper was less than optimal and has now been replaced by a smoother configuration. Since the energy of the artificially smoothened configuration is still larger than that of the annealed configuration this does not change our conclusion that, while the $\mathrm{Fe} / \mathrm{Cu}$ step-edge instability is driven by kinetics, energetics also plays a role.

(a) $\mathrm{Cu} / \mathrm{Cu}(100): \mathrm{t}=1.8 \mathrm{~s}$

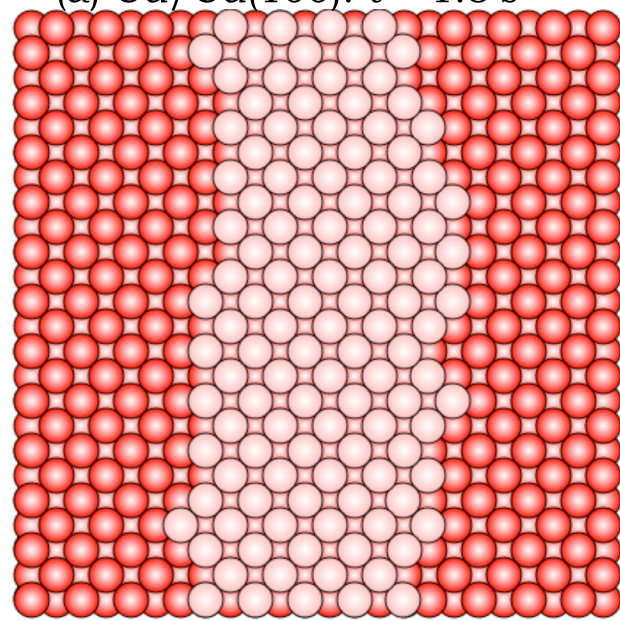

(c) $\mathrm{Fe} / \mathrm{Cu}(100): \mathrm{t}=0.12 \mathrm{~s}$

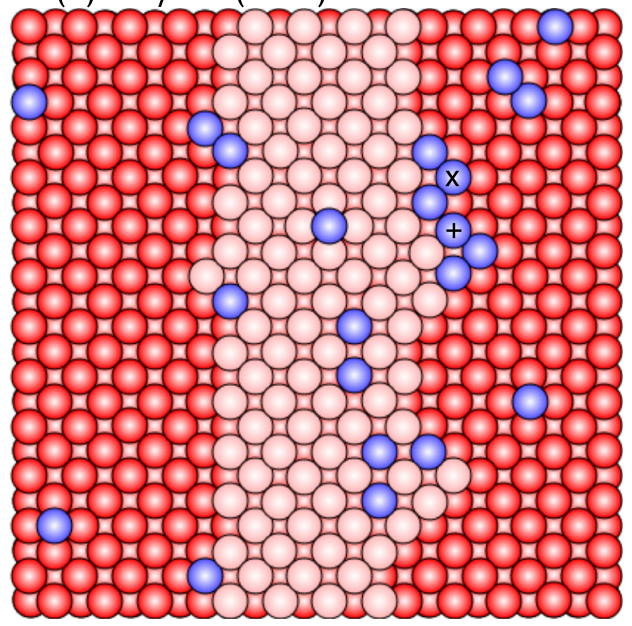

(b) $\mathrm{Fe} / \mathrm{Cu}(100): \mathrm{t}=0.0068 \mathrm{~s}$



(d) $\mathrm{Fe} / \mathrm{Cu}(100)$

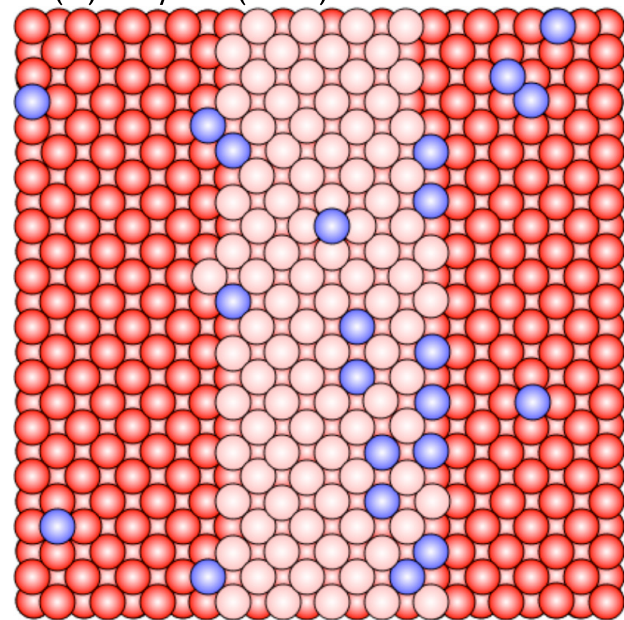

FIG. 5. (a)-(c) Evolution of surface morphology shown in Figs. 3(a) and 3(b) after annealing at $250 \mathrm{~K}$ for times indicated. (d) Artificially smoothened configuration (see text). In (b) the energy barrier for the embedding of an Fe atom marked as "+" is $0.6 \mathrm{eV}$, followed by dislocation release with an energy barrier of $0.053 \mathrm{eV}$. 